Check for updates

Cite this: RSC Adv., 2019, 9, 25967

\title{
Degradation of methylene blue by dielectric barrier discharge plasma coupled with activated carbon supported on polyurethane foam
}

\author{
Lihang Wu, Qinglong Xie, Yongbo Lv, Zhiyong Zhang, Zhenyu Wu, Xiaojiang Liang, \\ Meizhen Lu (D) and Yong Nie (D)*
}

\begin{abstract}
The degradation of methylene blue (MB) using a novel dielectric barrier discharge plasma reactor coupled with activated carbon supported polyurethane foam (AC/PUF) was investigated in this paper. The plasma reactor combining a glass bead-packed bed and a microporous plate was developed. The AC/PUF provided sufficient contact area between carbon media and pollutants and hence revealed a good MB removal capacity. The effects of input voltage and initial MB solution concentration on MB degradation efficiency were examined. Kinetic study indicated that plasma and AC/PUF in the coupled system had a good synergistic effect in MB degradation. The degradation efficiency of 100 ppm MB solution could reach $97.9 \%$ with 10 min treatment in the coupled system, which was close to that obtained by plasma treatment alone for $30 \mathrm{~min}$ (97.5\%). The COD removal in the plasma and AC/PUF coupled system (90.7\%) was much higher than that obtained by plasma treatment followed by AC/PUF adsorption (58.3\%). In addition, the energy yield $\left(G_{50}\right)$ of the coupled system was up to $38.3 \mathrm{~g} \mathrm{~kW}^{-1} \mathrm{~h}^{-1}$, suggesting great energy efficiency of the system. Moreover, repeated use experiments of AC/PUF showed the good utilization potential of the coupled system. Finally, a possible degradation pathway of MB was proposed.
\end{abstract}

Received 9th July 2019

Accepted 10th August 2019

DOI: $10.1039 / \mathrm{c} 9 \mathrm{ra} 05238 \mathrm{k}$

rsc.li/rsc-advances radicals is as high as $2.8 \mathrm{~V}$, only next to fluorine $\left(E_{0}: 3.06 \mathrm{~V}\right)$. Numerous hazardous compounds can be non-selectively oxidized and decomposed to $\mathrm{CO}_{2}, \mathrm{H}_{2} \mathrm{O}$ and inorganic ions by hydroxyl radicals usually at room temperature and normal pressure. $^{5}$ Photocatalysis, ${ }^{6}$ ozone, ${ }^{7}$ Fenton process ${ }^{8}$ and nonthermal plasma (NTP) technology ${ }^{9}$ are typical examples of AOPs. Among these methods, NTP can simultaneously generate various physical and chemical effects, including UV light, shockwave, electric field, and reactive species such as ${ }^{\circ} \mathrm{OH},{ }^{\circ} \mathrm{O}$, $\mathrm{O}_{3}$ and $\mathrm{H}_{2} \mathrm{O}_{2} \cdot{ }^{10}$ Thus, the application of NTP for elimination of organic compounds, especially those with high toxicity and low biodegradability in wastewater, has been widely studied. ${ }^{\mathbf{1 1}}$

Among NTP processes, dielectric barrier discharge (DBD) plasma has advantages of simple reactor structure and steady discharge state, which has been widely used in dyeing wastewater treatment. ${ }^{12-14}$ Reddy et $a .^{15}$ adopted a DBD reactor to investigate the degradation and mineralization of methylene blue (MB) solution. With the addition of $\mathrm{Fe}^{2+}$, highest $\mathrm{MB}$ degradation (over 95\%) and TOC removal $(21 \%)$ were obtained after 25 min treatment at $100 \mathrm{mg} \mathrm{L}^{-1} \mathrm{MB}$ concentration. Degradation of MB solution by different AOPs was compared by Aziz et al. ${ }^{16}$ The maximum MB mineralization of $88 \%$ was obtained using the DBD plasma under the argon atmosphere and in the presence of homogeneous $\mathrm{Fe}^{2+}$ catalyst which was due to the occurrence of an additional Fenton reaction. Iervolino et $a .^{17}$ studied the removal efficiency of MB by DBD reactor using oxygen as process gas. Complete degradation and mineralization of methylene blue was achieved after only $5 \mathrm{~min}$
China Petroleum and Chemical Industry Federation Engineering Laboratory of Biodiesel Technology, Zhejiang Provincial Key Laboratory of Biofuel, College of Chemical Engineering, Zhejiang University of Technology, Hangzhou, Zhejiang 310014, China. E-mail: ny_zjut@zjut.edu.cn; 201101390720@zjut.edu.cn; xieql@ zjut.edu.cn; 1437156976@qq.com; 799989893@qq.com; wuzhenyu@zjut.edu.cn; 291913062@qq.com; luzhen@zjut.edu.cn; Fax: +86 571-88320053; Tel: +86 5788320646 
of treatment time. Degradation of various textile dyeing wastewater under DBD plasma treatment was studied by Tichonovas et al. ${ }^{3}$ and high degradation efficiency was obtained for a wide variety (13 overall) of dyes. It suggested the promising applicability of DBD reactor in dyeing wastewater treatment. However, the sole plasma discharge treatment is widely considered economically-expensive since insufficient utilization of plasma active species would result in demand of significant amounts of electrical energy. In addition, mineralization is not achieved in many cases, which causes secondary problems with partially oxygenated products. ${ }^{15}$ Thus, it is urgent to develop more energy-efficient plasma reactor or combine the plasma reactor with other treatment methods to further improve the degradation and mineralization efficiency.

Carbon materials have been widely used in treating wastewater as adsorbents due to their excellent adsorption properties. $^{18}$ On the other hand, carbon materials give rise to the possibility of catalytic oxidation reactions on the carbon surface which in turn enhances the degradation efficiency of pollutants. ${ }^{19}$ The combination of activated carbon $^{20,21}$ or activated carbon fibers ${ }^{22,23}$ with plasma treatment showed enhanced performance of pollutants degradation and COD removal compared with plasma treatment alone. The integrated treatment process may synergize the advantages of their treatment performances, while overcoming their respective limitations. ${ }^{19}$ However, activated carbon can hardly distribute evenly in plasma reactor, especially in gas-liquid reactor, which causes inadequate contact between pollutants and carbon media and hence lower removal efficiency. In addition, the complicated fabrication process and high cost of activated carbon fibers limit their industrial application. Therefore, it is necessary to find some low-cost materials for activated carbon immobilization to improve its contact with the pollutants.

Polyurethane foams alone or combined with carbon media have been recently used for wastewater treatment by adsorption. ${ }^{24}$ Lefebvre et al. ${ }^{25}$ used activated carbon media immobilized on polyurethane foams (AC/PUF) for dye adsorption. The developed material provided sufficient contact between carbon media and pollutants and hence exhibited a good adsorption capacity. In addition, the material had advantages of large specific surface, high porosity, small pressure drop, good transport properties and low cost. However, no studies on AC/PUF coupled with DBD plasma reactor for dyeing wastewater treatment were reported.

In this work, a novel DBD plasma reactor combining glass beads packed bed and microporous plate was developed. The commercial AC/PUF was coupled with the novel plasma reactor for the treatment of dyeing wastewater. MB was selected as the model compound due to its stable molecular structure and wide usage. The AC/PUF material was characterized by scanning electron microscopy (SEM). The effects of input voltage and initial concentration of MB solution on MB degradation by DBD plasma with and without AC/PUF were examined. The MB degradation kinetics and the synergistic effect of DBD plasma and AC/PUF were investigated. In addition, the experiment for repeated use of AC/PUF was conducted to explore its application potential. Furthermore, the degradation byproducts were analyzed by liquid chromatography-mass spectrometry (LC-MS) and a possible degradation pathway for MB was proposed.

\section{Materials and methods}

\subsection{Materials}

Methylene blue (MB) was bought from Shanghai Titan Scientific Co., Ltd, Methanol for HPLC was purchased from Tianjin Siyou Scientific Co., Ltd. Reagents for chemical oxygen demand (COD) measurement were provided by Lianhua technology Co., Ltd. AC/ PUF was purchased from Suzhou Tanxuanfeng Activated carbon Co., Ltd. Deionized water was used for solution preparation. Unless otherwise stated, all of the chemicals are analytical reagent grade.

\subsection{Experimental setup and methods}

Fig. 1 shows the novel DBD plasma reactor comprising glass tank (inner diameter: $60 \mathrm{~mm}$; height: $100 \mathrm{~mm}$ ), porous diffuser plate (average pore size: $15-30 \mu \mathrm{m}$; diameter: $45 \mathrm{~mm}$; thickness: $5 \mathrm{~mm}$ ) and stainless steel plates (diameter: $30 \mathrm{~mm}$; height: $3 \mathrm{~mm}$ ) as ground and high voltage electrodes. The DBD reactor was energized by high voltage generated by a high frequency power supply (CTP-2000K, Nanjing Suman Electronics Co., Ltd.). The high voltage electrode was placed below the microporous diffuser plate and surrounded by glass beads. The ground electrode was immersed in liquid. The distance from high voltage electrode to porous diffuser plate was $4 \mathrm{~mm}$. The indoor air was fed to the DBD reactor from the bottom by an air pump. Discharge was initially generated in beads packed bed region and can spread into microporous plate with higher air flow rate. Thus, microdischarges were generated in micropores on the porous diffuser plate and in the gas film formed on the interface of plate and solution. The active plasma species including ozone formed in beads packed bed region and radical species generated in situ by microdischarges can directly react with contaminants in wastewater.

Batch experiments were conducted to explore the influences of different factors on the efficiency of $\mathrm{MB}$ degradation using plasma reactor with and without AC/PUF. Firstly, various input voltage $(6 \mathrm{kV}, 7 \mathrm{kV}, 8 \mathrm{kV})$ was adopted to investigate its effect on MB degradation efficiency. In addition, the effect of initial MB solution concentration $(50,75,100,150,200$ ppm) was explored. For each batch experiment, the total volume of the system was $100 \mathrm{~mL}$. The air flow rate of $1.5 \mathrm{~L} \mathrm{~min}^{-1}$ was chosen according to preliminary experiments. AC/PUF was sheared into round shape with $50 \mathrm{~mm}$ in diameter and $10 \mathrm{~mm}$ in height. Before use, it was cleaned by deionized water for eliminating impurities and dried at $323 \mathrm{~K}$ for $2 \mathrm{~h}$. The AC/PUF was put under ground voltage electrode and suspended in aqueous solution. Air was introduced into solution through porous plate and the formed bubbles rose up to AC/PUF, which can significantly increase the contact area of pollutants with AC/PUF. All the experiments were carried out at atmospheric pressure and ambient temperature. Each experiment was repeated at least three times.

\subsection{Analysis methods}

Surface morphology of AC/PUF samples was observed by SEM (TESCAN VEGA3) with an accelerating voltage of $10 \mathrm{kV}$. The functional groups on the surface of activated carbon were determined on a Bruker Tensor II Fourier transform infrared spectroscopy (FT-IR), with a resolution of $4 \mathrm{~cm}^{-1}$ and scanning 


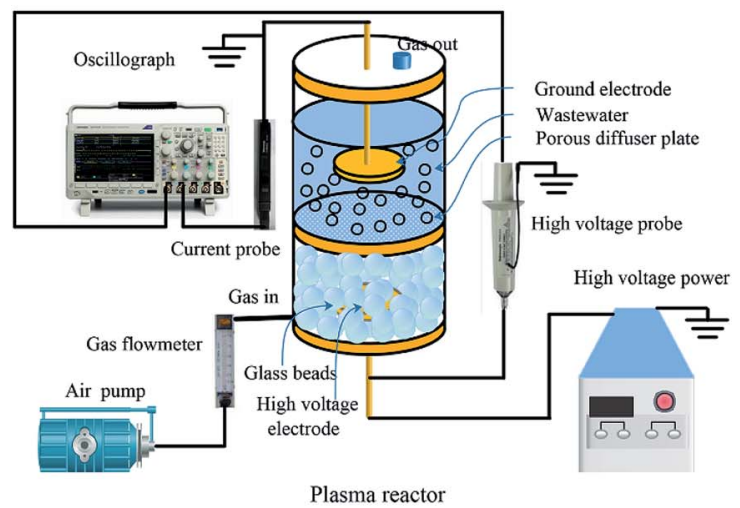

(a)

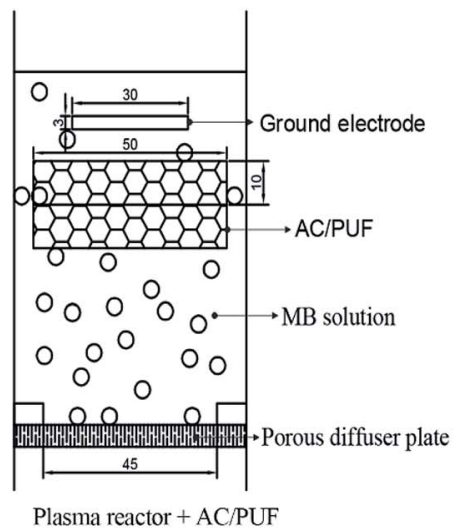

(b)

Fig. 1 (a) Diagram of the experimental apparatus; (b) 2D front view of the sole reactor with AC/PUF.

time of 64. The elemental composition of AC/PUF was analyzed using an Elementar vario macro (Germany).

Samples were taken during specific intervals. The concentration of MB solution was quantitatively analyzed using Agilent Cary 60 UV-Visible spectrophotometer at the wavelength of $664 \mathrm{~nm}$. For high concentration, the sample was diluted first for accurate measurement. The MB degradation efficiency $\eta$ can be described as:

$$
\eta(\%)=\frac{C_{0}-C_{t}}{C_{0}} \times 100
$$

where $C_{0}$ and $C_{t}$ are attributed to the MB concentrations at $t=$ 0 and after $t$ min of the treatment, respectively. COD was analyzed by $5 \mathrm{~B}-6 \mathrm{C}$ (V8) multi-parameter water quality analyzer (Lianhua Technology Co., Ltd.). The COD removal was calculated using the following equation:

$$
\mathrm{COD}(\%)=\frac{\mathrm{COD}_{0}-\mathrm{COD}_{t}}{\mathrm{COD}_{0}} \times 100
$$

where $\mathrm{COD}_{0}$ and $\mathrm{COD}_{t}$ refer to COD of initial solution and the solution at time $t$.

A current probe (TCP-0030A, Tektronix) was used to measure the current $(I)$ applied to the DBD reactor, with the signal detected and shown in a digital oscilloscope (DPO 3052, Tektronix). A $1000: 1$ high voltage probe (P6015A, Tektronix) was used to measure the voltage $(U)$ applied to the DBD reactor, with the signal detected and shown in a digital oscilloscope (DPO 3052, Tektronix). ${ }^{26}$ The discharge power for the packed-bed DBD reactor was calculated using:

$$
P=f \times \int_{0}^{T} U(t) \times I(t) \mathrm{d} t
$$

The energy yield for MB degradation can be calculated by the following equation:

$$
Y\left(\mathrm{~g} \mathrm{~kW}^{-1} \mathrm{~h}^{-1}\right)=\frac{C\left(\mathrm{~g} \mathrm{~L}^{-1}\right) \times V(\mathrm{~L}) \times \frac{1}{100} \times \eta(\%)}{P(\mathrm{~kW}) \times t(\mathrm{~h})}
$$

where $C$ is initial MB concentration, $V$ is the volume of the solution $(100 \mathrm{~mL}), \eta$ is degradation efficiency at time $t, P$ is power and $t$ is time. $G_{50}\left(\mathrm{~g} \mathrm{~kW}^{-1} \mathrm{~h}^{-1}\right)$ (energy yield when $\eta=$ $50 \%$ ) was calculated by $\eta=50 \%$ and corresponding time determined by degradation kinetics.

The degradation products after 10 min treatment with and without AC/PUF were characterized using liquid chromatography-mass spectrometry (LC-MS) (Waters 2695ThermoFisher LCQTM Deca XP plus) in the positive ion mode. The product samples were injected into the ESI source at a flow rate of $0.5 \mathrm{~mL} \mathrm{~min}^{-1}$. The mixture of methanol and ultrapure $(9: 1)$ was used as mobile phase.

\section{Results and discussion}

\subsection{Characterization of the AC/PUF sample}

Fig. 2 showed the image of the commercial AC/PUF material and SEM images of AC/PUF before and after treating $\mathrm{MB}$ wastewater. Fig. $2 \mathrm{~b}$ revealed that initial AC/PUF had relatively rough surface with abundant pores, which was utilized to adsorb the organic compounds and support active sites for pollutants degradation. It was obvious that there were no substances attached at first. However, some particles (seen in Fig. 2c) were distributed on the surface of $\mathrm{AC} / \mathrm{PUF}$ and in the pores of $\mathrm{AC} / \mathrm{PUF}$ after adsorption, indicating $\mathrm{MB}$ molecules were adsorbed. In addition, the morphology and structure of AC/PUF had no change after their use, suggesting the stability of the AC/PUF material.

FTIR spectra of orginal AC/PUF and AC/PUF after adsorption are shown in Fig. 3. No obvious difference in peaks between both curves was observed, suggesting no change in functional groups on the carbon surface after use, which further indicated the stability of the AC/PUF material.

The results of elemental composition of AC/PUF were shown in Table 1. The contents of $\mathrm{N}$ and $\mathrm{S}$ in $\mathrm{AC} / \mathrm{PUF}$ were slightly increased, which can be attributed to the adsorption of $\mathrm{MB}$ molecules and MB intermediates.

\subsection{The effect of input voltage on MB degradation}

Discharge voltage is directly related to the generation of the amount of plasma active species, which is relevant to the $\mathrm{MB}$ 


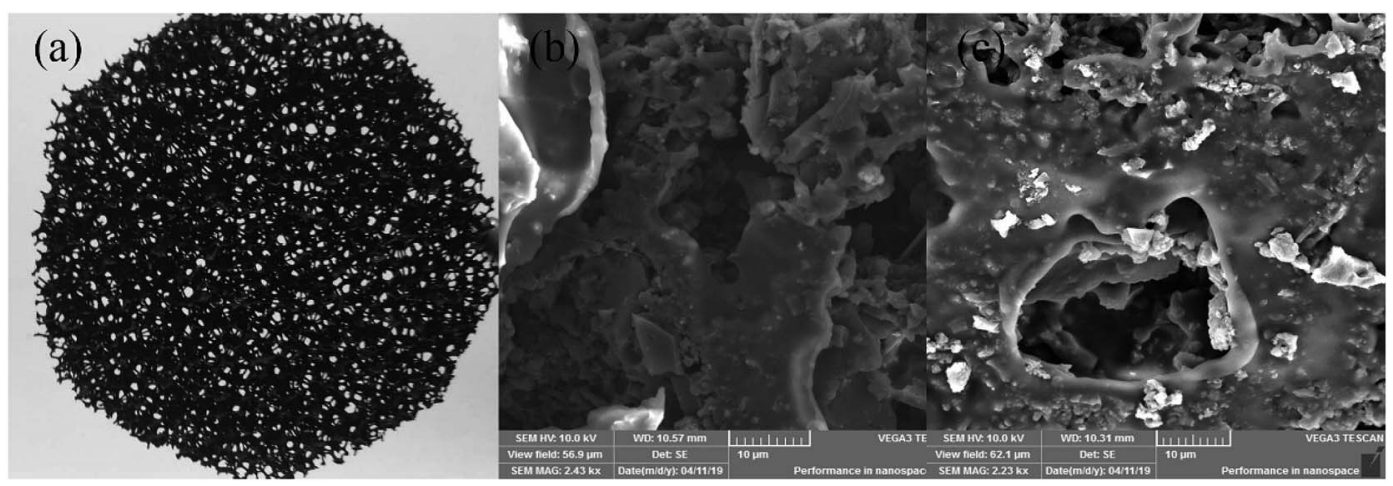

Fig. 2 Commercially AC/PUF (a) and surface morphology of (b) original AC/PUF; (c) AC/PUF after adsorption.

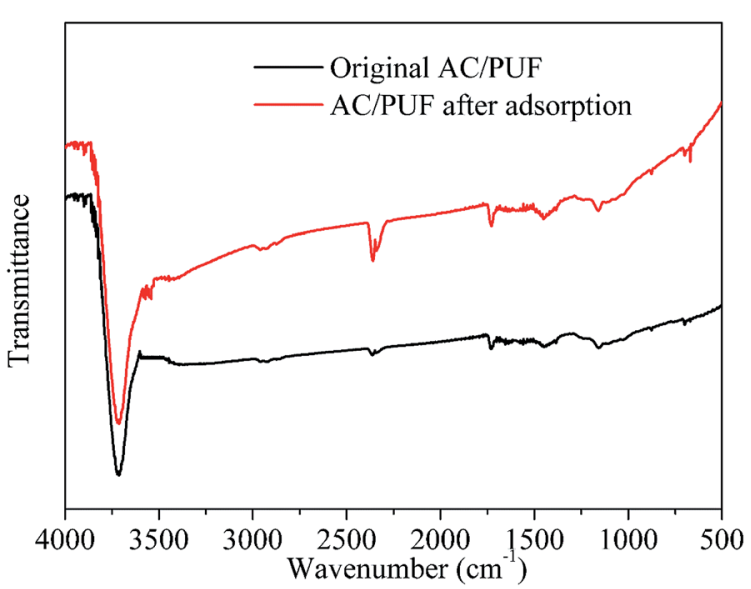

Fig. 3 FTIR spectra of orginal AC/PUF and AC/PUF after adsorption.

Table 1 Elemental composition of AC/PUF before and after adsorption

\begin{tabular}{lcccc}
\hline & $\mathrm{C} \%$ & $\mathrm{H} \%$ & $\mathrm{~N} \%$ & $\mathrm{~S} \%$ \\
\hline AC/PUF before adsorption & 78.22 & 3.902 & 0.28 & 0.789 \\
AC/PUF after adsorption & 78.08 & 2.541 & 0.43 & 1.102
\end{tabular}

degradation efficiency. Herein, we investigated the influence of applied voltage on the MB degradation efficiency, as shown in Fig. 4a. Obviously, MB degradation efficiency by plasma coupled with two pieces of AC/PUF was higher than that by merely plasma at the same input voltage. The increasing voltage enhanced the MB removal in both plasma and the coupled systems. For 100 ppm MB solution, the degradation efficiency with plasma alone increased from $75.7 \%$ to $95.7 \%$ as input voltage increased from $6 \mathrm{kV}$ to $8 \mathrm{kV}$, compared with that increased from $96.7 \%$ to $98.8 \%$ in the coupled system of plasma with AC/PUF. It was because that larger input voltage led to larger injected power and thus more plasma active species were generated, which resulted in higher MB degradation efficiency.

The energy yield $Y\left(\mathrm{~g} \mathrm{~kW}^{-1} \mathrm{~h}^{-1}\right)$ was introduced to illustrate the energy efficiency during $\mathrm{MB}$ degradation process. It can be clearly seen in Fig. 4b that the energy yield in the coupled system was larger than that in sole system at all the three voltage. The largest energy yield was up to $38.3 \mathrm{~g} \mathrm{~kW}^{-1} \mathrm{~h}^{-1}$ at 7 $\mathrm{kV}$ after $1 \mathrm{~min}$ treatment for the coupled system. Moreover, the results indicated that the energy yield gradually decreased with the increasing degradation time under every operation condition. The reason was that $\mathrm{MB}$ concentration gradually decreased with the increasing degradation efficiency over time, resulting in a lower collision probability between MB molecules and
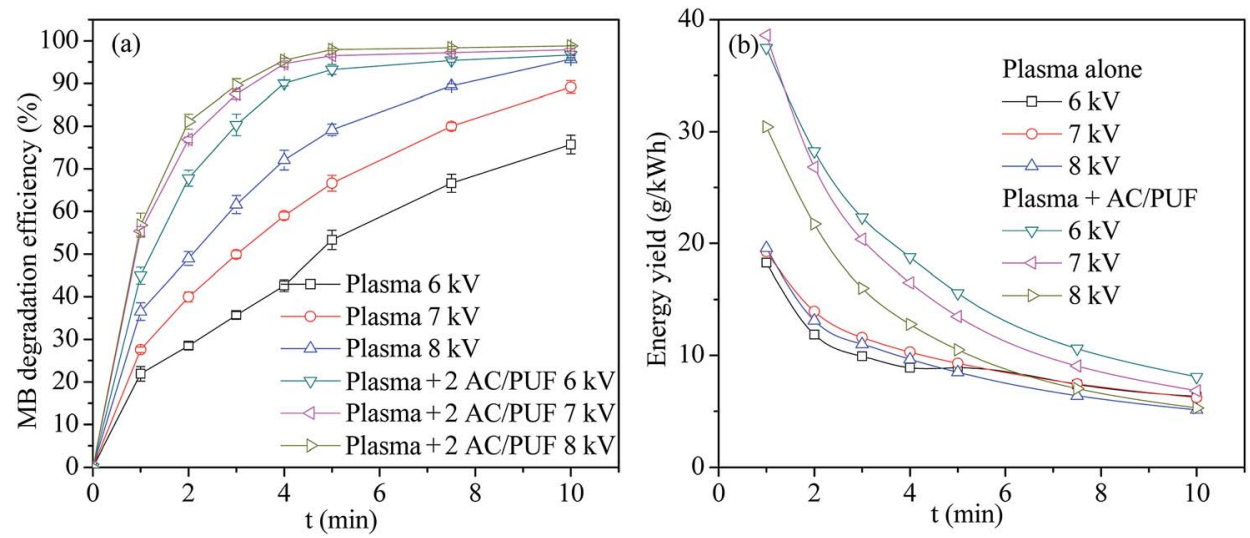

Fig. 4 (a) The effect of input voltage on MB degradation efficiency (b) energy yield versus time at different voltage (2 AC/PUF: two pieces of AC/ PUF). 

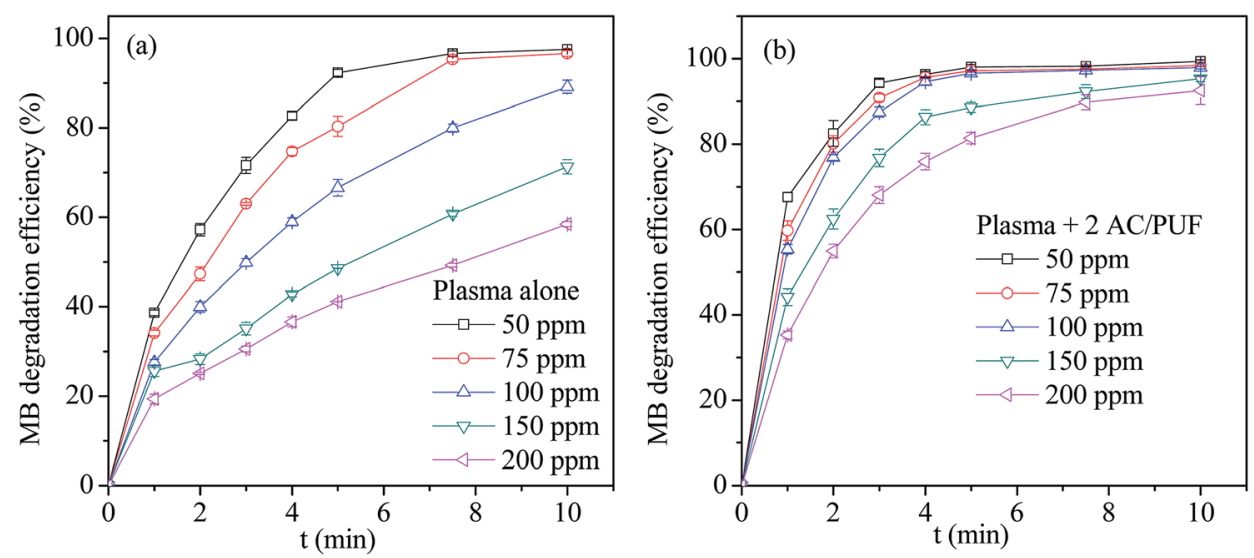

Fig. 5 The effect of initial concentration on MB degradation efficiency by (a) plasma reactor alone and (b) the coupled system (2 AC/PUF: two pieces of AC/PUF).

plasma active species, which finally led to less MB removal per unit of energy consumption in reaction system. In addition, energy yield decreased with increasing input voltage, suggesting that an appropriate voltage was needed to acquire largest energy efficiency of degradation system. Considering both degradation efficiency and energy yield, the input voltage of $7 \mathrm{kV}$ was used in the following experiments.

\subsection{The effect of initial solution concentration on MB degradation}

The effect of initial MB solution concentration on degradation efficiency by plasma reactor and the coupled system was displayed in Fig. 5. For both systems, the MB degradation efficiency at lower initial $\mathrm{MB}$ concentration was higher than that at higher initial $\mathrm{MB}$ concentration after $10 \mathrm{~min}$ treatment. The main reason lied in the fact that the amount of plasma active species formed in the discharge process was maintained at specific concentration level for the constant energy input. It can be also noted that the MB degradation efficiency with plasma alone reached $97.5 \%, 96.5 \%$ and $89.2 \%$ with only $10 \mathrm{~min}$ treatment time for three initial $\mathrm{MB}$ concentration $(50 \mathrm{ppm}$, $75 \mathrm{ppm}, 100 \mathrm{ppm}$ ), respectively. It proved that the proposed plasma reactor is effective for $\mathrm{MB}$ degradation. Moreover, $\mathrm{MB}$ degradation efficiency in the coupled system was obviously higher than that in plasma reactor at every initial solution concentration, which was attributed to the addition of AC/PUF.

\subsection{MB degradation kinetics}

Fig. 6 showed MB degradation efficiency by plasma or AC/PUF alone and the coupled system with different pieces of AC/PUF. It can be observed that MB can be partly adsorbed by AC/PUF due to its great adsorption capacity. In addition, the $\mathrm{MB}$ degradation efficiency was significantly increased in the presence of $\mathrm{AC} / \mathrm{PUF}$ in plasma reactor, which can be attributed to the adsorption capacity of AC/PUF and decomposition of pollutants in active sites. ${ }^{22}$ It was noteworthy that increasing amount of AC/PUF enhanced the MB degradation efficiency. After 5 min treatment, the MB degradation efficiency reached $88.5 \%$ with one piece AC/PUF and $96.5 \%$ with two pieces of AC/
PUF coupled into plasma reactor, while it was only $66.6 \%$ with plasma alone. In a word, the coupled system can largely reduce treatment time to achieve the same degradation efficiency, which finally enhanced energy efficiency of plasma treatment.

Additionally, MB degradation efficiency by activated carbon with or without plasma was also investigated. The amount of AC used was equal to that supported on two pieces of AC/PUF. As shown in Fig. 6, compared with AC/PUF, the MB degradation efficiency was obviously lower when AC was used. It was mainly because AC was distributed unevenly in $\mathrm{MB}$ solution without being supported on PUF, which caused inadequate contact between pollutants and carbon media and hence the decrease in MB degradation efficiency. The PUF material had advantages of large specific surface, high porosity, small pressure drop, good transport properties and low cost. The combination of carbon and PUF can effectively improve the contact between pollutants and carbon.

In order to compare the degradation rate of different treatment methods, degradation kinetic parameters were determined. The degradation of MB can be described by pseudo firstorder kinetics. ${ }^{11}$ As shown in Table 2, the correlation coefficients were obtained by plotting $\ln \left(C_{0} / C\right)$ versus time. The

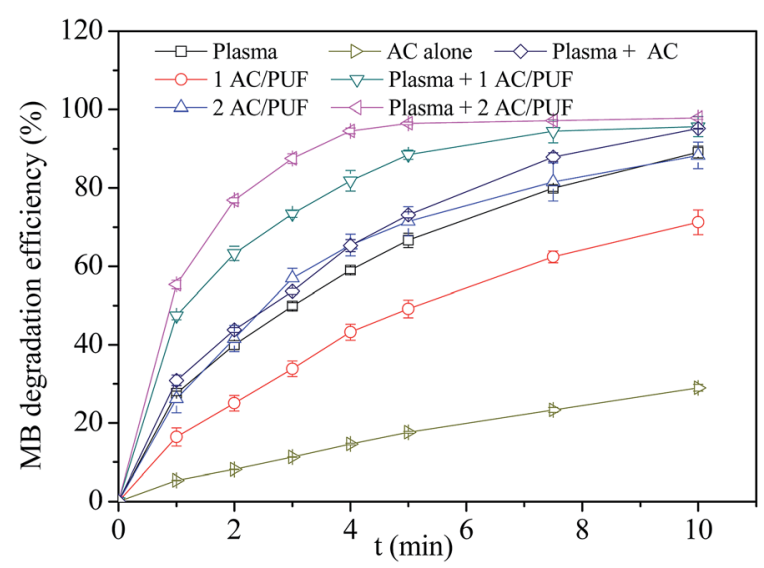

Fig. 6 Comparison of plasma alone, AC/PUF alone and the coupled system (initial solution concentration $=100 \mathrm{ppm}$, input voltage $=7 \mathrm{kV}$, 1/2 AC/PUF: one/two pieces of AC/PUF). 
Table 2 Comparison of different parameters with various treatment methods

\begin{tabular}{lllll}
\hline & $k\left(\mathrm{~min}^{-1}\right)$ & $R^{2}$ & $\mathrm{SF}$ & $G_{50}\left(\mathrm{~g} \mathrm{~kW}^{-1} \mathrm{~h}^{-1}\right)$ \\
\hline AC & 0.0321 & 0.9980 & - & - \\
$1 \mathrm{AC} /$ PUF & 0.1234 & 0.9965 & - & - \\
$2 \mathrm{AC} / \mathrm{PUF}$ & 0.2115 & 0.9873 & - & - \\
Plasma + 0 AC/PUF & 0.2135 & 0.9970 & - & 11.6 \\
Plasma + AC & 0.2970 & 0.9891 & 1.2093 & 16.2 \\
Plasma + 1 AC/PUF & 0.4095 & 0.9885 & 1.2155 & 24.7 \\
Plasma + 2 AC/PUF & 0.6794 & 0.9954 & 1.5986 & 38.3
\end{tabular}

highest $k$ value $\left(0.6794 \mathrm{~min}^{-1}\right)$ was obtained when introducing two pieces of AC/PUF into degradation system. The kinetic constant of the coupled system with $2 \mathrm{AC} / \mathrm{PUF}$ was 3.18 times that with plasma alone and 3.21 times that with 2 AC/PUF adsorption alone. In addition, the kinetic constant of the coupled system with AC/PUF was larger than that with AC, which suggested more effective $\mathrm{MB}$ degradation by plasma coupled with AC/PUF. According to eqn (5), it can be observed that the kinetic constant of $\mathrm{MB}$ degradation in plasma reactor coupled with AC/PUF was higher than the sum of that by plasma alone and adsorption alone ( $\mathrm{SF}>1)$. It indicated that plasma and $\mathrm{AC} / \mathrm{PUF}$ in the coupled system had a good synergistic effect in MB degradation.

$$
\mathrm{SF}=\frac{k_{\mathrm{P}+\mathrm{AC} / \mathrm{PUF}}}{k_{\mathrm{P}}+k_{\mathrm{AC} / \mathrm{PUF}}}
$$

\subsection{Comparison of various treatment methods}

Further comparative experiments were conducted to investigate the synergistic effect of plasma and AC/PUF in the coupled system. MB solution was treated by plasma discharge for certain time ( $5 \mathrm{~min}, 10 \mathrm{~min}, 20 \mathrm{~min}$ or $30 \mathrm{~min}$ ), followed by the addition of two pieces of AC/PUF to adsorb MB molecules or intermediates for the same time.

The degradation efficiency and COD removal for various treatment methods are shown in Fig. 7. Both MB degradation efficiency and COD removal by plasma coupled with AC/PUF for
5 min were significantly larger than sum of that by plasma treatment for 5 min followed by AC/PUF adsorption for another $5 \mathrm{~min}$. It indicated that certain synergistic effect existed for the combination of plasma and AC/PUF. The degradation efficiency of $100 \mathrm{ppm}$ MB solution could reach $97.9 \%$ with only 10 min treatment in the coupled system, which was close to that obtained by plasma treatment alone for $30 \mathrm{~min}(97.5 \%)$. In addition, the COD removal in the plasma and AC/PUF coupled system was much higher than that obtained by plasma treatment followed by AC/PUF adsorption. It was also possibly due to existence of the synergistic effect. The dissolved ozone generated by plasma discharge was more easily decomposed to ${ }^{\circ} \mathrm{OH}$ at the presence of $\mathrm{AC} / \mathrm{PUF},{ }^{27}$ which enhanced the decomposition of MB molecules and its intermediates. Guo et al. ${ }^{28}$ investigated a hybrid gas-liquid discharge plasma system coupled with granular activated carbon for bisphenol A degradation. Decreasing ozone and increasing $\mathrm{OH}$ concentration was observed after the addition of activated carbon under plasma discharge, which illustrated ozone can be catalyzed by activated carbon and converted into ${ }^{\circ} \mathrm{OH}$. Possible mechanism can be described by the following reactions (6)-(10): ${ }^{9}$

$$
\begin{aligned}
& \mathrm{O}_{3}+\mathrm{H}-\mathrm{AC} / \mathrm{PUF}-\mathrm{H} \rightarrow \text { AC/PUF-O }+\mathrm{H}_{2} \mathrm{O}_{2} \\
& \mathrm{O}_{3}+\mathrm{AC} / \mathrm{PUF}-\mathrm{OH} \rightarrow{ }^{\circ} \mathrm{O}_{2}-\mathrm{AC} / \mathrm{PUF}+{ }^{\circ} \mathrm{OH} \\
& \mathrm{O}_{3}-\mathrm{AC} / \mathrm{PUF} \rightarrow \mathrm{O}_{2}+{ }^{\circ} \mathrm{O}-\mathrm{AC} / \mathrm{PUF} \\
& \mathrm{O}_{3}+{ }^{\circ} \mathrm{O}-\mathrm{AC} / \mathrm{PUF} \rightarrow{ }^{\circ} \mathrm{O}_{2}+\mathrm{O}+\mathrm{AC} / \mathrm{PUF} \\
& \cdot \mathrm{OH}+\text { intermediates } \rightarrow \mathrm{CO}_{2}+\mathrm{H}_{2} \mathrm{O}
\end{aligned}
$$

The interaction between plasma and AC/PUF improved the MB degradation and mineralization. Moreover, the activated carbon can provide more concentrated centers for oxidation of pollutants by reactive species. ${ }^{9}$ In a word, the coupled system of plasma with AC/PUF had good synergistic effect, indicating its potential for dyeing wastewater treatment.

The energy yields by plasma alone and the coupled system were as high as 9.3 and $13.5 \mathrm{~g} \mathrm{~kW}^{-1} \mathrm{~h}^{-1}$, respectively. As shown
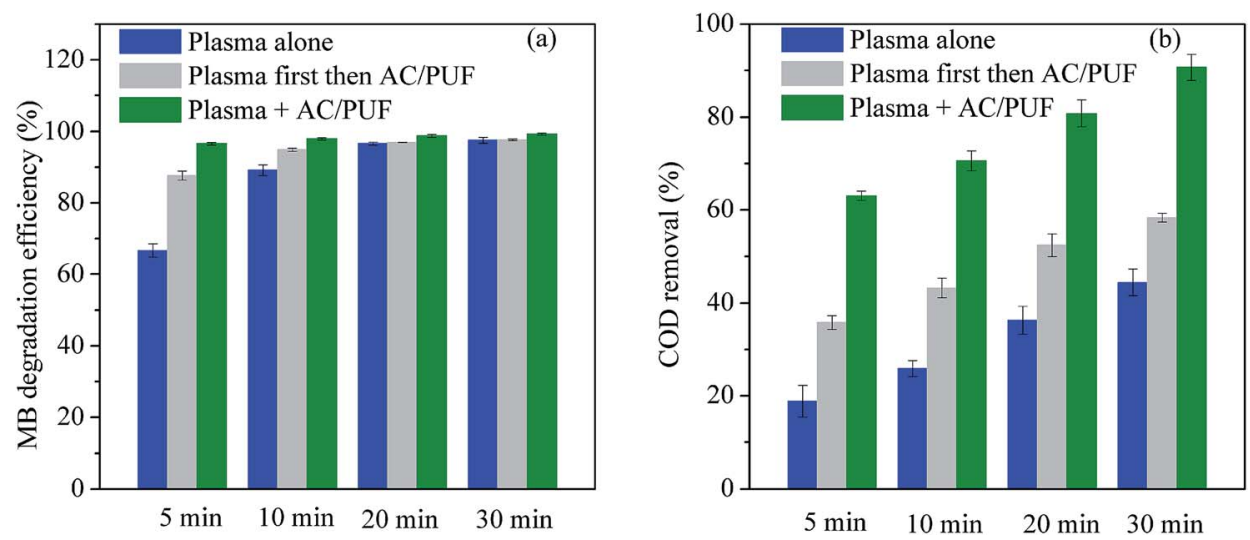

Fig. 7 Comparison of the effect of different treatment methods on (a) MB degradation efficiency, and (b) COD removal (initial solution concentration $=100 \mathrm{ppm}$, input voltage $=7 \mathrm{kV}$ ). 
Table 3 Comparison of organic degradation in this and some earlier studies ${ }^{a}$

\begin{tabular}{|c|c|c|c|c|}
\hline Pollutants & Type of operation condition & Conditions & $\begin{array}{l}\text { Energy yield } \\
\left(\mathrm{g} \mathrm{kW}^{-1} \mathrm{~h}^{-1}\right)\end{array}$ & Ref. \\
\hline Methylene blue & Plasma & $V_{0}: 0.1 \mathrm{~L}, C_{0}: 100 \mathrm{ppm}, t: 5 \mathrm{~min}$, power: $8.6 \mathrm{~W}$, air: $1.5 \mathrm{~L} \mathrm{~min}^{-1}$ & 9.3 & This study \\
\hline Triclosan & $\mathrm{DBD}+\mathrm{ACF}$ & $V_{0}: 0.12 \mathrm{~L}, C_{0}: 10 \mathrm{ppm}, t: 18 \mathrm{~min}$, power: $60 \mathrm{~W}$ & 6.2 & 22 \\
\hline Triclocarban & $\mathrm{DBD}+\mathrm{TiO}_{2} / \mathrm{ACF}$ & $V_{0}: 0.1 \mathrm{~L}, C_{0}: 10 \mathrm{ppm}, t: 30 \mathrm{~min}$, power: $38 \mathrm{~W}$, air: $0.4 \mathrm{~L} \mathrm{~min}^{-1}$ & 0.045 & 23 \\
\hline Methyl orange & Pulsed discharge + ACF & $V_{0}: 0.2 \mathrm{~L}, C_{0}: 80 \mathrm{ppm}, t: 21 \mathrm{~min}, V: 46 \mathrm{kV}, F: 100 \mathrm{~Hz}$, air: $1 \mathrm{~L} \mathrm{~min} \min ^{-1}$ & 4.7 & 29 \\
\hline
\end{tabular}

${ }^{a} V_{0}$ : liquid volume; $C_{0}$ : initial concentration; $t$ : treatment time; $V$ : input voltage; $F$ : input frequency; ACF: activated carbon fiber.

in Table 3, the results were much larger than those reported in previous studies. Furthermore, in order to avoid interference from intermediates at MB degradation efficiency of higher than $50 \%$, energy yield at $50 \%$ degradation $\left(G_{50}\right)$ was adopted. Aziz et $a l .{ }^{16}$ reported the energy yield for $50 \%$ conversion of MB using different AOPs in the range of 0.13 and $20.5 \mathrm{~g} \mathrm{~kW}^{-1} \mathrm{~h}^{-1}$. As listed in Table 2, the highest $G_{50}\left(38.3 \mathrm{~g} \mathrm{~kW}^{-1} \mathrm{~h}^{-1}\right)$ was obtained by plasma coupled with two pieces of AC/PUF, which was relatively high compared with other studies, ${ }^{\mathbf{1 5}, 17}$ suggesting great energy efficiency of the coupled system.

\subsection{Repeated use of AC/PUF samples}

Repeated use of AC/PUF was important to its applicability for wastewater treatment. The recycling experiment was conducted by reusing AC/PUF for five times. As clearly seen in Fig. 8a, little change in the degradation efficiency of $\mathrm{MB}$ was observed with recycle times, suggesting the stability of AC/PUF adsorption capacity under plasma. In addition, recycling experiments of two pieces of AC/PUF alone without plasma for MB removal were also conducted. As shown in Fig. 8b, the MB removal efficiency was dramatically decreased after five cycles, which was mainly due to the reduced adsorption capacity of AC/PUF. By comparison, the MB degradation efficiency with the coupled method was slightly decreased from $97.9 \%$ to $96.6 \%$ after five runs. It can be ascribed to the self-regeneration of AC/PUF resulting from the degradation of pollutants adsorbed on AC/PUF by active species such as ${ }^{\circ} \mathrm{OH}$. In addition, the COD removal of MB solution was slightly reduced from $70.6 \%$ to $66.7 \%$ after five runs in the coupled system. Therefore, the method of plasma coupled with AC/PUF has potential for practical application.

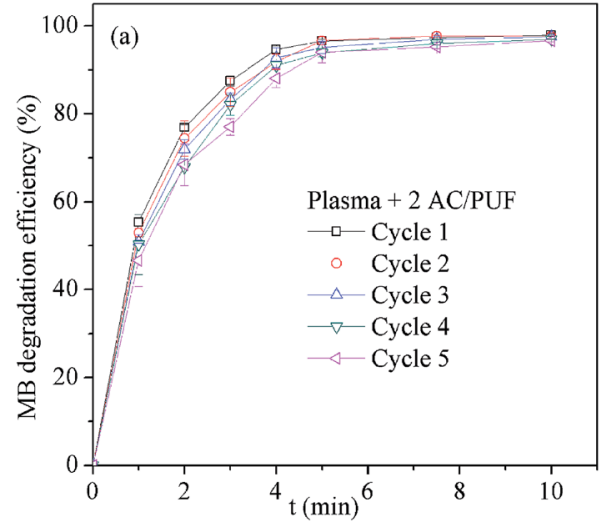

\subsection{Degradation mechanism}

In order to investigate the degradation mechanism of $\mathrm{MB}$ using plasma with and without AC/PUF, LC-MS was used to explore the possible degradation intermediates. The results showed little difference in degradation intermediates between plasma treatment with and without AC/PUF. The intermediates were mainly produced by high-energy electron attack, ozonation and hydroxylation. Similar results were reported by Wang et al. ${ }^{30}$ Possible pathway was put forward as shown in Fig. 9. The existence of MB molecule was confirmed by peak at $\mathrm{m} / \mathrm{z}$ of 284 . With the presence of high-energy electrons, MB molecule was converted into fragments with peaks at $m / z$ of $270,256,228$, which were attributed to demethylation. In addition, hydroxyl radicals were widely acknowledged as the main species to degrade MB molecules. The organics with $\mathrm{m} / \mathrm{z}$ of 292 and 343 were determined by LCMS, which was due to hydroxylation reaction. ${ }^{13}$ Huang et al. proposed the mechanism of MB degradation by plasma treatment based on the bond dissociation energy theory. ${ }^{31}$ The lower the bond dissociation energy was, the easier the bond was broken. The bond energy of $\mathrm{CH}_{3}-\mathrm{N}\left(\mathrm{CH}_{3}\right) \mathrm{C}_{6} \mathrm{H}_{5}$ and $\mathrm{C}_{6} \mathrm{H}_{5}-\mathrm{S}-\mathrm{C}_{6} \mathrm{H}_{5}$ was calculated to be only 70.8 and $76 \mathrm{kcal} \mathrm{mol}^{-1}$, respectively. Thus, the compound with peaks at $\mathrm{m} / \mathrm{z}$ of $273,262,247$ were determined. Additionally, possible ring breaking products $(\mathrm{m} / \mathrm{z}=170,135$, 125) were proposed, which can be arised from hydroxyl radicals and ozone. The possible intermediates of MB decomposition can be ionic by-products such as acetate, oxalate, and sulfate. ${ }^{\mathbf{1 6}}$ Finally, all of the intermediates were decomposed and mineralized into $\mathrm{CO}_{2}, \mathrm{H}_{2} \mathrm{O}, \mathrm{SO}_{4}{ }^{2-}$ and $\mathrm{NO}_{3}{ }^{-}$. Different from plasma alone, compounds with peaks at $\mathrm{m} / z=398$ and 309 were also found for the coupled system, which can be attributed to the

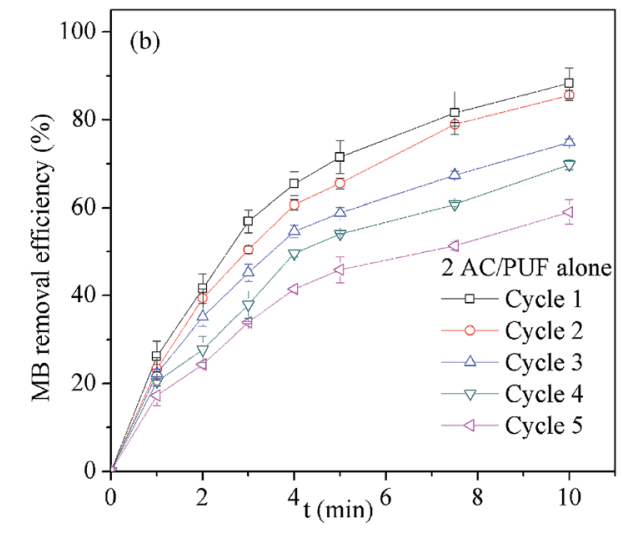

Fig. 8 Effect of repeated use of AC/PUF on MB removal efficiency (a) Plasma + 2 AC/PUF, (b) 2 AC/PUF alone (2 AC/PUF: two pieces of AC/PUF). 

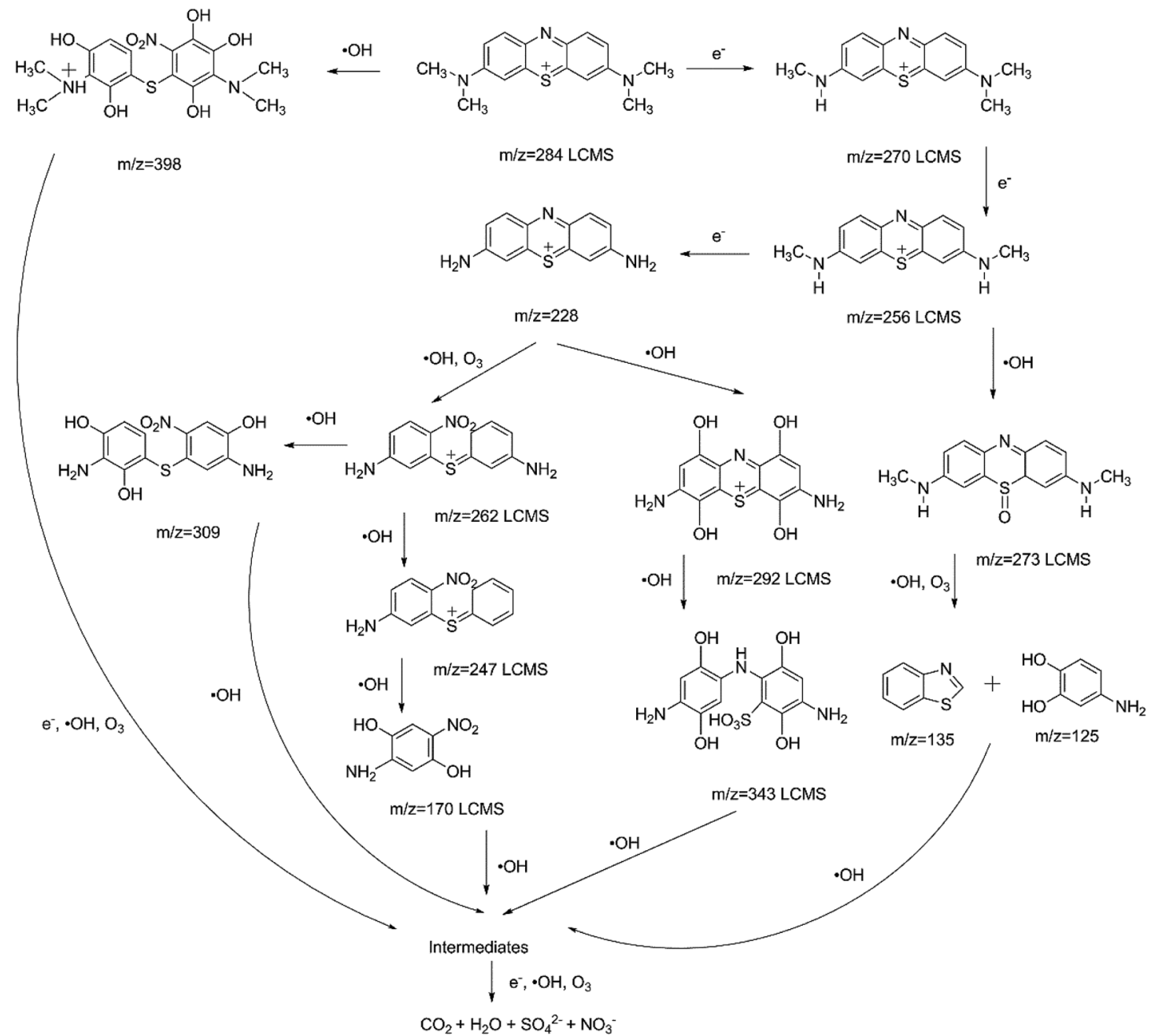

Fig. 9 Possible pathway of MB degradation.

generation of more hydroxyl radicals with the presence of AC/PUF in plasma reactor.

\section{Conclusions}

In this paper, MB degradation was investigated in a novel DBD plasma reactor coupled with a commercial material AC/PUF. The results revealed that $\mathrm{MB}$ molecules can be effectively degraded in the plasma reactor. The degradation efficiency increased from $89.2 \%$ to $95.7 \%$ and $97.9 \%$ when one piece and two pieces of AC/PUF were added into the plasma reactor, respectively. The coupled system of plasma and AC/PUF exhibited much better MB degradation effect than plasma coupled with AC. In addition, high COD removal (90.7\%) and $G_{50}$ value $\left(38.3 \mathrm{~g} \mathrm{~kW}^{-1} \mathrm{~h}^{-1}\right)$ were obtained in the coupled system of plasma and AC/PUF. Kinetic study and comparison experiments of different treatment methods indicated the coupled system had a good synergistic effect in MB degradation. Moreover, the AC/PUF can be repeatedly used for five times with negligible change, suggesting good utilization potential. Finally, high energy electron, ozone and hydroxyl radical were acknowledged as the main species in MB degradation.

\section{Conflicts of interest}

There are no conflicts to declare.

\section{References}

1 W. Li, B. Mu and Y. Yang, Bioresour. Technol., 2019, 277, 157170.

2 V. Katheresan, J. Kansedo and S. Y. Lau, J. Environ. Chem. Eng., 2018, 6, 4676-4697.

3 M. Tichonovas, E. Krugly, V. Racys, R. Hippler, V. Kauneliene, I. Stasiulaitiene and D. Martuzevicius, Chem. Eng. J., 2013, 229, 9-19.

4 J. L. Wang and L. J. Xu, Crit. Rev. Environ. Sci. Technol., 2012, 42, 251-325.

5 K. Paździor, L. Bilińska and S. Ledakowicz, Chem. Eng. J., DOI: 10.1016/j.cej.2018.12.057.

6 P. A. Pekakis, N. P. Xekoukoulotakis and D. Mantzavinos, Water Res., 2006, 40, 1276-1286.

7 M. Peña, M. Coca, G. González, R. Rioja and M. T. García, Chemosphere, 2003, 51, 893-900. 
8 A. Babuponnusami and K. Muthukumar, J. Environ. Chem. Eng., 2014, 2, 557-572.

9 B. Jiang, J. Zheng, S. Qiu, M. Wu, Q. Zhang, Z. Yan and Q. Xue, Chem. Eng. J., 2014, 236, 348-368.

10 P. Bruggeman and C. Leys, J. Phys. D: Appl. Phys., 2009, 42, 53001.

11 K. H. Hama Aziz, H. Miessner, A. Mahyar, S. Mueller, D. Kalass, D. Moeller and K. M. Omer, Sep. Purif. Technol., 2019, 216, 51-57.

12 E. S. M. Mouele, J. O. Tijani, O. O. Fatoba and L. F. Petrik, Environ. Sci. Pollut. Res., 2015, 22, 18345-18362.

13 L. O. d. B. Benetoli, B. M. Cadorin, V. Z. Baldissarelli, R. Geremias, I. G. de Souza and N. A. Debacher, J. Hazard. Mater., 2012, 237-238, 55-62.

14 A. S. Bansode, S. E. More, E. A. Siddiqui, S. Satpute, A. Ahmad, S. V. Bhoraskar and V. L. Mathe, Chemosphere, 2017, 167, 396-405.

15 P. Manoj Kumar Reddy, B. Rama Raju, J. Karuppiah, E. Linga Reddy and C. Subrahmanyam, Chem. Eng. J., 2013, 217, 4147.

16 K. H. Hama Aziz, A. Mahyar, H. Miessner, S. Mueller, D. Kalass, D. Moeller, I. Khorshid and M. A. M. Rashid, Process Saf. Environ. Prot., 2018, 113, 319-329.

17 G. Iervolino, V. Vaiano and V. Palma, Sep. Purif. Technol., 2019, 215, 155-162.

18 L. Wu, Q. Xie, Z. Wu, T. Zheng, X. Lu, M. Lu, Y. Nie and J. Ji, Desalin. Water Treat., 2018, 131, 272-281.
19 B. Jiang, J. Zheng, X. Lu, Q. Liu, M. Wu, Z. Yan, S. Qiu, Q. Xue, Z. Wei, H. Xiao and M. Liu, Chem. Eng. J., 2013, 215-216, 969-978.

20 Y. Zhang, J. Zheng, X. Qu and H. Chen, J. Colloid Interface Sci., 2007, 316, 523-530.

21 G. Qu, D. Liang, D. Qu, Y. Huang, T. Liu, H. Mao, P. Ji and D. Huang, Chem. Eng. J., 2013, 228, 28-35.

22 L. Xin, Y. Sun, J. Feng, J. Wang and D. He, Chemosphere, 2016, 144, 855-863.

23 J. Wang, Y. Sun, J. Feng, L. Xin and J. Ma, Chem. Eng. J., 2016, 300, 36-46.

24 E. E. Baldez, N. F. Robaina and R. J. Cassella, J. Hazard. Mater., 2008, 159, 580-586.

25 L. Lefebvre, G. Agusti, A. Bouzeggane and D. Edouard, Catal. Today, 2018, 301, 98-103.

26 Y. Nie, Q. Zheng, X. Liang, D. Gu, M. Lu, M. Min and J. Ji, Environ. Sci. Technol., 2013, 47, 7934-7939.

27 U. Jans and J. Hoigné, Ozone: Sci. Eng., 1998, 20, 67-90.

28 H. Guo, N. Jiang, J. Li and Y. Wu, Vacuum, 2018, 156, 402410.

29 Y. Zhang, B. Sun, S. Deng, Y. Wang, H. Peng, Y. Li and X. Zhang, Chem. Eng. J., 2010, 159, 47-52.

30 B. Wang, B. Dong, M. Xu, C. Chi and C. Wang, Chem. Eng. Sci., 2017, 168, 90-100.

31 F. Huang, L. Chen, H. Wang and Z. Yan, Chem. Eng. J., 2010, 162, 250-256. 